\title{
Analysis of the Rating of the Russian Federation in the Global Economy in Terms of Socio-economic Development in the Conditions of Political and Economic Sanctions
}

\author{
Galina M. Kolpakova \\ Julia V. Evdokimova* \\ Moscow engineering university, Russian state social university, Russian Federation \\ *Corresponding Email uaevdokimova@mail.ru
}

Doi:10.5901/mjss.2015.v6n6s7p139

\begin{abstract}
Article presents the analysis of rating indicators in the period from 2011 to 2015 evaluating the socio-economic situation of Russia in the world economy. A number of critical indicators and criteria are considered, such as gross domestic product, gross national income, index of social progress. Critical activities that minimize the effects of the crisis prevailing in the Russian economy are evaluated.
\end{abstract}

Keywords: economic growth, social progress, Russian Federation, global economy

\section{Introduction}

Transition of economy of the Russian Federation to the new model of development providing growth of rates of economic development, achievement of higher level of quality of life and welfare of the population - these tasks are paramount for Russia according to strategy of social and economic development of the Russian Federation. However, conditions of realization of this strategy seriously became complicated in 2014-15 and were followed by approach of financial crisis. The main signs of a crisis situation in the country are falling of rates of economic growth, devaluation of national currency, a high rate of inflation, leaving of the foreign companies from the Russian market, falling of the real income of the population. Already following the results of the first half of 2014 in economy of Russia there came stagnation, investment activity decreased, intensity in labor market remains, growth of the real located income is slowed down, there is mass increase of the capital (World Bank, 2015b).

Falling of prices of oil was the main negative tendency for Russia, $50 \%$ of which income of the federal budget arrive from export of oil and gas. The Russian economy also faced a number of economic and political sanctions that was an additional negative factor.

According to the World Bank, in 2015 average price of oil will make 58 US dollars for barrel, and in 2016 - 63.6 US dollars for barrel. Reduction in 2015 of real GDP for $2.7 \%$ is predicted, in 2016 this indicator will make $0.7 \%$, and by 2017 will grow to $2.5 \%$. Increase of investment activity in 2016 - 2017 years on condition of cancellation of sanctions until the end of 2016 is possible (World Bank, 2015c).

The forecast of social and economic development of Russia by 2030 provided an exit to other, much higher level of social and economic development, namely: movement of Russia in a world rating from the 16th on the 7th place on an indicator of welfare of the population, GDP growth per capita to 38-52 thousand dollars of the USA (Ministry of Economic Development of the Russian Federation, 2015). The forecast also provided that 2014 Russia will be able to enter the five of the leading countries of the world on economic indicators, however the situation developed extremely adversely for the Russian Federation.

\section{An Assessment of a Rating of the Russian Federation on Rates of Economic Growth in 2011-2014}

It is possible to judge modern economic and social situation of the Russian Federation on a number of foreign researches. One of the main macroeconomic indicators characterizing results of functioning of economy of the state for a certain period of time is the gross domestic product defining rates of development of national economy. Two methods of calculation of GDP are standardly applied: a method of summation of the income existing in economy, or a method of summation of all made expenses. The research of rates of economic growth of 214 states conducted by the World bank 
for 2011-2014, (World Development Indicators) shows the results given in the tab. 1 (World Bank, 2015a):

Table 1. The analysis of growth rates of gross domestic product of the leading states and change of their place in world economy for 2011-2014

\begin{tabular}{lccccc}
\hline Country & $\begin{array}{c}\text { Place in a } \\
\text { Rating of 2011 }\end{array}$ & $\begin{array}{c}\text { Place in a } \\
\text { Rating of 2012 }\end{array}$ & $\begin{array}{c}\text { Place in a } \\
\text { Rating of 2013 }\end{array}$ & $\begin{array}{c}\text { Place in a } \\
\text { Rating of 2014 }\end{array}$ & $\begin{array}{c}\text { GDP Gain for } \\
\text { the Period, \% }\end{array}$ \\
\hline United States of America & 1 & 1 & 1 & 1 & 112.26 \\
China & 2 & 2 & 2 & 2 & 138.28 \\
Japan & 3 & 3 & 3 & 3 & 77.90 \\
Germany & 4 & 4 & 4 & 4 & 102.68 \\
France & 5 & 5 & 5 & 6 & 98.85 \\
Brazil & 6 & 7 & 7 & 7 & 89.71 \\
Great Britain & 7 & 6 & 6 & 5 & 113.50 \\
Italy & 8 & 8 & 8 & 8 & 94.12 \\
Russian Federation & 9 & 9 & 9 & 10 & 97.69 \\
India & 10 & 11 & 10 & 9 & 112.58 \\
\hline
\end{tabular}

In these ratings, the GDP level is expressed in US dollars without amendment on inflation of the countries that owing to distinctions on rates of inflationary depreciation distorts an overall picture a little. Nevertheless, it is possible to reveal a number of certain tendencies: firmness of paramount positions of China, USA, Japan and Germany, rather stable structure of the first ten countries of a rating. In dynamics the following changes are noted: the forward annual gain is revealed in China, the USA and Great Britain, systematic annual decrease in the GDP level is noted in Japan and Brazil. The Russian Federation in 2014 went down one position below, than in the previous three years, with the corresponding decrease in the GDP level (\$2 016112133645 - in 2012, \$2 079024782973 - in 2013, \$1 860597922763 - in 2014)

The following indicator characterizing state of the economy of the state - the gross national income. The table 2 testify to the place taken by the Russian Federation on this indicator in world economy.

Table 2. The analysis of growth rates of a gross national income of the leading states and change of their place in world economy for 2011-2014

\begin{tabular}{lccccc}
\hline Country & $\begin{array}{c}\text { Place in a } \\
\text { Rating of 20111 }\end{array}$ & $\begin{array}{c}\text { Place in a } \\
\text { Rating of 2012 }\end{array}$ & $\begin{array}{c}\text { Place in a Rating } \\
\text { of 2013 }\end{array}$ & $\begin{array}{c}\text { Place in a Rating } \\
\text { of 2014 }\end{array}$ & $\begin{array}{c}\text { VND Gain for the } \\
\text { Period, \% }\end{array}$ \\
\hline United States of America & 1 & 1 & 1 & 1 & 111.92 \\
China & 2 & 2 & 2 & 2 & 149.70 \\
Japan & 3 & 3 & 3 & 3 & 92.44 \\
Германия & 4 & 4 & 4 & 4 & 101.51 \\
France & 5 & 5 & 5 & 5 & 98.70 \\
Great Britain & 6 & 6 & 6 & 6 & 108.60 \\
Brazil & 7 & 7 & 7 & 7 & 107.61 \\
Italy & 8 & 8 & 8 & 8 & 93.96 \\
India & 9 & 9 & 10 & 9 & 115.96 \\
Russian Federation & 10 & 10 & 9 & 10 & 124.76 \\
\hline
\end{tabular}

Continuous growth of an indicator is shown by China, the USA, Great Britain and India. So continuous falling is noted in Italy. In Russia growth of an indicator on three periods (from 2011 to 2013 inclusive), was replaced by insignificant decrease in 2014 (2011 - \$1 546825158 133, 2012 - \$1 822828301 613, 2013 - \$1 981668 976 550, 2014-1 930435 $\$ 724507$ ) (The website of the world Bank, GNI, Atlas method, 2015).

However on rates of a gain of a gross national income of the Russian Federation takes for the analyzed time period the second place in the world after China.

\section{An Assessment of a Rating of the Russian Federation on the Level of Social Progress in 2014-2015}

The Social Progress Index measures positions of social progress and public wellbeing of the states. The index of social progress includes four key principles:

- Application of exclusively social and ecological indicators for an assessment, without economic criteria as 
association of social and economic indicators complicates differentiation of cause and effect.

- Productivity research, but not expenses as the main objective consists in measurement of the gained effect, but not enclosed resources.

- Universal approach for the countries with any level of the income as generally similar researches are concentrated on the poor countries with their problems in the field of social progress. Understanding on what healthy society of any country is founded, it is possible to develop the universal scenario.

- Effectiveness as the practical tools capable to promote implementation of social programs, social progress are necessary for the states and business.

The index is based on 12 components and 52 separate indicators that allows to carry out the analysis of concrete areas. Definition of an index of social progress is carried out in a complex and comprehensively. The indicator is accented on three questions: Whether the satisfaction of necessary needs of the citizens provides the state? Whether activities for maintenance and strengthening of social wellbeing are carried out? Whether can living in this state in full open the potential?

Answers to the matters are submitted in three directions:

1) Basic needs of the person - food, basic medical care, providing with water and housing, personal security.

2) Wellbeing bases - access to basic knowledge, access to information and communications, health and wellbeing, stability of ecosystems.

3) Possibilities of the person - the personal rights, a personal liberty, tolerance and inklyuziya, access to the advanced tendencies in education (Social Progress Imperative, 2014; Social Progress Index, Methodology, 2015; Social Progress Index, 2015).

The index consists for $61 \%$ from statistical data, for $12 \%$ - of polls, for $25 \%$ - of estimates of experts. In 2015133 states, in 2014 - 132 countries were subject to research (see tab. 3).

Table 3. Rating of the countries of the world on the level of social development in 2014-2015

\begin{tabular}{lcc}
\hline Country & Place in a Rating, 2014 & Place in a Rating, 2015 \\
\hline New Zealand & 1 & 5 \\
Switzerland & 2 & 3 \\
Iceland & 3 & 4 \\
Netherlands & 4 & 9 \\
Norway & 5 & 1 \\
Sweden & 6 & 2 \\
Canada & 7 & 6 \\
Finland & 8 & 7 \\
Denmark & 9 & 8 \\
Australia & 10 & 10 \\
Russia & 80 & 71 \\
\hline
\end{tabular}

Source: (Social Progress Imperative, 2014; Social Progress Index, 2015).

The structure of the countries which entered ten leaders in social development in two years remained invariable. However in dynamics indicators changed very strongly. Most seriously New Zealand and the Netherlands gave in, and seriously improved the indicators Norway and Sweden. Russia considerably strengthened the situation in a rating in two years.

Level of social progress can be measured also by means of an index of human development which pays off as the arithmetic-mean size of three indexes: income, longevity and education (Kolpakova, 2015). According to the Report on human development in the Russian Federation for 2013 Russia is included into group of the countries with the high level of an index of human development.

Summing up the results of the carried-out analysis, it is possible to draw a conclusion that, of course, introduction of political and economic sanctions to the Russian Federation affected its economic and social situation. However the Russian Federation kept the leading positions and still enters ten the leading countries on growth rates of GNP and VND, and on the level of social development it managed to raise significantly the rating in world economy.

\section{Contents of the Plan of Anti-recessionary Actions in the Russian Federation}

In January, 2015 for systematization of processes of improvement of economy of the state, the plan of anti-recessionary 
actions was created. Structural changes in economy, decrease in rates of inflation, positive growth rates in medium-term prospect are planned. Soon events for import substitution activization, export maintenance, stimulation of development of small and medium business, attraction of current assets and investment resources for optimum cost will be held. Compensation of inflationary expenses to certain socially unprotected categories of citizens, optimization of the budgetary expenses, full implementation of public obligations is provided. Introduction of the mechanism of sanitation will allow to strengthen a banking system. The exception of inefficient expenses will lead to reduction of the federal budget for $10 \%$. Reduction of the budgetary financing won't affect the social sphere, financing on ensuring defense capability of the state, execution of the international obligations, and also support of agriculture. Further optimization of structure of the federal budget provides decrease in expenses within 3 years for $5 \%$ annually (The Government of the RF, 2015).

The course of social and economic development planned before crisis in general remains: invariable there will be a realization of the state programs including directed on improvement of quality of health systems and education, stimulation of private investments, the accelerated realization of 'road maps', improvement of control and supervising governmental activities of activity. Attraction of direct foreign investments, creation of innovative infrastructure will proceed. The course on optimization of tax privileges, tax system in general within the approved 'road map' directed on improvement to the Russian Federation of tax administration (Evdokimova, 2014) won't change. A main objective in this case is creation of conditions for simplification of interaction of business and tax authorities. Reforming of pension system and the existing social privileges proceeds. Further growth of quality of system of public administration is necessary.

\section{Conclusion}

Thus, proceeding from the analysis of the rating indicators characterizing a number of economic and social criteria, and researches of the plan of anti-recessionary actions it is possible to draw a conclusion that, in general, despite the most difficult economic and political situation, economic and social situation of the Russian Federation didn't undergo sharp uncontrollable negative changes for 2014 and 2015. Owing to this fact, it is possible to expect that at application of system, adequate measures, the state will be able to adapt for the most difficult conditions and to reach that the planned level which was provided shortly before emergence of financial crisis.

\section{References}

Evdokimova, YU.V. (2014). Improvement of tax administration in the Russian Federation. Economy and management of innovative technologies, 1 (28), 8.

Kolpakova, G. M. (2015). Multilevel model of the valuable mechanism of managing of information society. Moskow: IIU MGOU.

Ministry of Economic Development of the Russian Federation (2015). The forecast of long-term social and economic development of the Russian Federation for the period till 2030. Information and legal system 'Garant'. [Online] Available: http://base.garant.ru/7030 9010/ (November 12, 2015).

Social Progress Imperative (2014). A rating of the countries of the world on the level of social progress of 2014. Information- analytical portal Center of humanitarian technologies. [Online] Available: http://gtmarket .ru/news/2014/04/14/6688 (November 16, 2015).

Social Progress Index (2015). Official website. [Online] Available: http://www.socialprogressimperative.org/data/spi/methodology (November 16, 2015).

The Government of the RF (2015). The plan of priority actions for providing a sustainable development of economy and social stability in 2015 (the order of the Government of the Russian Federation of January 27, 2015 No. 98-r). [Online] Available: http://government.ru/media/files/7QoLbdOVNPc.pdf (November 16, 2015).

World Bank (2015a). Data. GDP / GNI, Atlas method. [Online] Available: http://data.worldbank.org/indicator (November 15, 2015).

World Bank (2015b). The report on the Russian economy. [Online] Available: http://www.worldbank.org/content/dam/Worldbank/ document/eca/russia/rer32-rus.pdf (November 20, 2015).

World Bank (2015c). The world Bank has adjusted the economic growth forecast for Russia for 2015 and 2016. Online] Available: http://www.worldbank.org/ru/news/press-release/2015/06/01/world-bank-revises-its-growth-projections-for-russia-for-2015-and2016 (November 20, 2015). 